\title{
LONG-TERM EVALUATION OF TREATMENT FOR FUNCTIONAL TRICUSPID REGURGITATION WITH REGURGITANT VOLUME: CHARACTERISTIC DIFFERENCES BASED ON PRIMARY CARDIAC LESION
}

Takaki Sugimoto, MD

Masayoshi Okada, MD

Nobuchika Ozaki, MD

Tadashi Hatakeyama, MD

Toshihiro Kawahira, MD
Objectives: The aim of this study was to characterize differences in the long-term effects of treatment for functional tricuspid regurgitation based on the primary cardiac lesion. Methods: Ninety-six patients with valvular heart disease and 32 patients with atrial septal defects associated with tricuspid regurgitation were studied. The tricuspid annular diameter was associated with evidence of right heart failure. In valvular heart disease, a Kay annuloplasty was performed in 33 patients with a tricuspid annular diameter of $\geq 40 \mathrm{~mm}$ to $44 \mathrm{~mm}$, a modified De Vega annuloplasty in 12 patients with a tricuspid annular diameter of $\geq 45$ $\mathrm{mm}$ to $49 \mathrm{~mm}$, and a modified De Vega annuloplasty, annuloplasty using a Carpentier ring, or tricuspid valve replacement in each of 4 patients with a tricuspid annular diameter of $\geq 50 \mathrm{~mm}$. In atrial septal defects, a Kay annuloplasty was performed in 11 patients with a tricuspid annular diameter of $\geq 45 \mathrm{~mm}$ to $49 \mathrm{~mm}$, and a modified De Vega annuloplasty was performed in 5 patients with a tricuspid annular diameter of $\geq \mathbf{5 0}$ mm. A mean follow-up period was 79 months after operation. Results: In the patients with a tricuspid annular diameter of $<50 \mathrm{~mm}$, the hemodynamic and clinical findings and tricuspid regurgitation remarkably improved. In the patients with valvular heart disease with a tricuspid annular diameter of $\geq \mathbf{5 0} \mathbf{~ m m}$, however, the right heart parameters also showed improvement but less so when compared with those patients with a tricuspid annular diameter of $<50 \mathrm{~mm}$. In addition, 4 patients undergoing a modified De Vega annuloplasty have had a gradual increase in tricuspid regurgitation and clinical manifestations late after the operation. In contrast, all 5 patients with atrial septal defects with a tricuspid annular diameter of $\geq 50 \mathrm{~mm}$ have shown remarkable improvement, similar to those with a tricuspid annular diameter of $<50$ $\mathbf{m m}$. Preoperative analyses revealed that the right heart function in atrial septal defects had not deteriorated to the same extent as in valvular heart disease. Conclusion: In the patients with a severely dilated tricuspid anulus $(\geq 50 \mathrm{~mm})$, the postoperative change of tricuspid regurgitation differed between those patients with valvular heart disease and atrial septal defects. (J Thorac Cardiovasc Surg 1999;117:463-71) eft-sided valvular heart disease (VHD) and left-toright cardiac shunt disease often cause functional

\footnotetext{
From the Department of Surgery, Division II, Kobe University School of Medicine, Kobe, Japan.

Received for publication Sept 12, 1997; revisions requested Nov 12, 1997; revisions received Oct 5, 1998; accepted for publication Oct 5,1998 .

Address for reprints: Takaki Sugimoto, MD, Department of Surgery, Division II, Kobe University School of Medicine, 7-5-2 Kusunoki-cho, Chuo-ku, Kobe, 650-0017, Japan.

Copyright (C) 1999 by Mosby, Inc.

$0022-5223 / 99 \$ 8.00+0 \quad \mathbf{1 2 / 1 / 9 4 9 7 0}$
}

tricuspid regurgitation (TR) as the result of right ventricular pressure or volume overload. ${ }^{1-8}$ With respect to surgical treatment of functional TR, surgeons have advocated not repairing the valve, ${ }^{1}$ performing a variety of tricuspid annuloplasty procedures, ${ }^{2-9}$ or performing valve replacement. ${ }^{9-12}$ Because of the differences in both cause and treatment, TR may decrease gradually after correction of the primary cardiac lesion. ${ }^{1}$ However, in some patients, significant TR remains after annuloplasty. ${ }^{5-9}$ There may be differences in the degree of TR after surgical repair on the basis of the primary cardiac lesion responsible for the TR. This 
study presents the long-term effects of treatment for TR and shows characteristic differences on the basis of the primary cardiac lesion.

\section{Methods}

Patients. From April 1985 to September 1995, 276 patients underwent valve operation for acquired VHD, and 60 patients underwent repair of a secundum atrial septal defect (ASD). Among the patients with VHD, 85 patients who had organic TR or who underwent isolated aortic valve operation or concomitant cardiac procedures such as coronary artery bypass grafting were excluded from the study. Organic TR was defined as prolapse of the cusps, rheumatic valvulitis, or destruction of the valve apparatus because of infective endocarditis, diagnosed with preoperative echocardiography. Seven patients who died of cardiac complications early after the operation and 8 patients who had repeat operations because of dysfunction of the left-side valve repairs were also excluded from the study. Among the patients with ASD, 10 patients who had organic TR or who underwent concomitant coronary artery bypass grafting, mitral valve operation, or operation for anomalous pulmonary venous drainage were also excluded from the study. Among the remaining patients, 96 patients (30 men and 66 women) with a mitral valve lesion or mitral and aortic valve lesions and 32 patients (14 men and 18 women) with ASD associated with functional TR were enrolled in the study. For the patients with VHD, the main left-sided lesions were mitral stenosis in 56 patients and mitral regurgitation in 24 patients. Sixteen patients had both mitral and aortic valve lesions. Open mitral commissurotomy was performed in 4 patients; mitral valve replacement was performed in 76 patients, and combined mitral and aortic valve replacement was performed in 16 patients. All ASDs were closed with a patch.

Evaluation of TR. Echocardiographic studies were performed within 5 days before the operation when the patient was hemodynamically stable. Two-dimensional and Doppler echocardiography was performed with Toshiba SSH-65A and SSH-140A equipment (Toshiba Corp, Tokyo, Japan) with a 2.5 MHz transducer. Each patient lay quietly for 15 minutes in a supine position and underwent the procedure in the left lateral decubitus position while breathing quietly. The TR jet was observed in the following 3 cross-sectional views: parasternal long-axis view of the right ventricular inflow tract, apical 4-chamber view, and parasternal short-axis view at the level of the aortic valve.

Calculation of TR volume. First, TR was observed in the 2 right-angle cross-sectional views with 2-dimensional color Doppler echocardiography. The width of the base of the TR jet at a right angle $(a, b)$ was measured at the tricuspid valve position in each view. The cross-sectional area $(S)$ of the base of the TR jet was calculated as an elliptical shape $(S=\pi / 4$. $\mathrm{ab}$ ), where the major and minor axes were a and b. Next, a continuous-wave Doppler echocardiogram was recorded from the center of the base of the TR jet (the most accelerated point of the functional TR occurring as the result of dila- tion of the anulus). The TR volume of 1 unit area $(V u)$ at this point was calculated by integrating the parabolic flow velocity signal of the echocardiogram during the ejection phase $(\mathrm{Vu}=2 / 3 \cdot \mathrm{vt} ; v$, peak velocity; $t$, duration of regurgitation $)$. The TR volume per beat $\left(\mathrm{V}_{\mathrm{TR}}\right)$ is equal to the sum of the volume of 1 unit area per cross-sectional area, which is assumed to build up a conical shape. This is because the volume of 1 unit area decreases in accordance with distance from the center of the TR jet. The $\mathrm{V}_{\mathrm{TR}}$ can be calculated by the following formula: $1 / 3 \cdot S \cdot V u=\pi / 18 \cdot$ abvt (Fig 1). Because all of the patients underwent atrial fibrillation, each value for $\mathrm{V}_{\mathrm{TR}}$ was obtained from an average of more than 5 heart beats. In 2dimensional color Doppler echocardiography, the Doppler gain was set at the maximum level where no background noise was seen. In the continuous-wave Doppler echocardiogram, the angle between the Doppler beam and the direction of the TR jet was provided within 20 degrees. The echocardiogram was passed through a high-pass filter $(1600 \mathrm{~Hz})$ to eliminate the influence of the movement of the intracardiac structure and was recorded on a stripchart at a paper speed of $50 \mathrm{~mm} / \mathrm{s}$.

The tricuspid annular diameter (TAD) was measured at end-diastole from 3 cross-sectional views (parasternal longaxis view of the right ventricular inflow tract, apical 4-chamber view, and parasternal short-axis view at the level of the aortic valve) obtained with 2-dimensional echocardiography with a $3.75 \mathrm{MHz}$ transducer. This value was defined as the maximum length of the tricuspid anulus determined by the longest distance between the bases of the opposing 2 leaflets in these 3 views.

Other parameters. All patients underwent preoperative right heart catheterization studies, including cineangiography at the same time as Doppler studies. The right ventricular volume was obtained from the biplane cineangiograms by the area-length method ${ }^{13}$ on an average of 5 heart beats excluding premature contractions.

The degree of heart failure was based on New York Heart Association (NYHA) functional class, the degree of hepatomegaly, and indocyanine green measurement.

Treatment of TR. There was a significant correlation between preoperative TAD and $\mathrm{V}_{\mathrm{TR}}$ in the VHD group $(r=$ $0.87 ; P<.0001)$ and the ASD group $(r=0.88 ; P<.0001)$. The slope of the correlation line (TAD: $\mathrm{x}$-axis, $\mathrm{V}_{\mathrm{TR}}: \mathrm{y}$-axis) was steeper for the VHD group $(y=1.41 \mathrm{x}-46.0)$ than the ASD group $(y=1.11 x-37.6$; Fig 2). In the patients with VHD with a TAD of $40 \mathrm{~mm}$ or more and the patients with ASD with a TAD of $45 \mathrm{~mm}$ or more, hepatomegaly, disappearance rate of indocyanine green ( $\mathrm{k}$ value), right atrial mean pressure (RAMP), right ventricular end-diastolic pressure (RVEDP), and right ventricular end-diastolic volume index (RVEDVI) had deteriorated to the point that surgical repair for TR was necessary (Tables I and II).

TR was prospectively treated as follows in this series. In VHD, TR was ignored in 39 patients with a TAD of less than $40 \mathrm{~mm}$. A Kay ${ }^{2}$ annuloplasty was performed in 33 patients with a TAD of less than $45 \mathrm{~mm}$; a modified De Vega annulo- 


\section{【2-DIMENSIONAL DOPPLER ECHOCARDIOGRAPHY】}

Parasternal long-axis view of right ventricular inflow tract
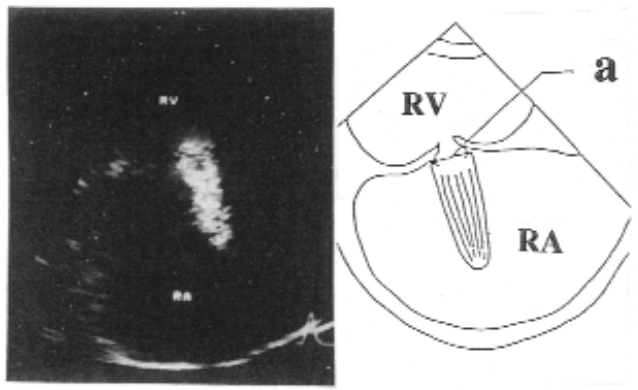

Cross-sectional area of the base of TR jet
Apical 4-chamber view

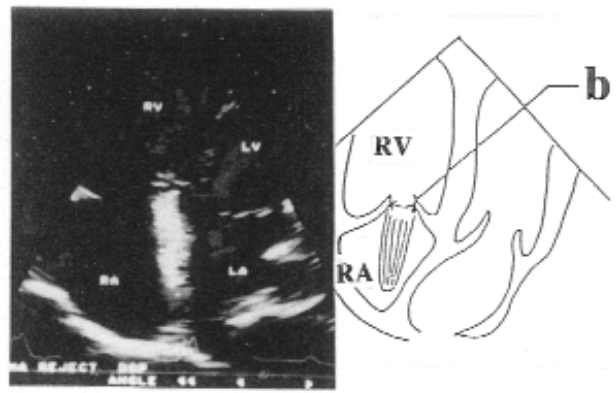

$\mathrm{S}($ ellipse $)=\frac{\pi}{4} \cdot \mathbf{a b}$

( $a, b$; width of TR jet flow from each right-angled view)

\section{【CONTINUOUS-WAVE DOPPLER ECHOCARDIOGRAM】}
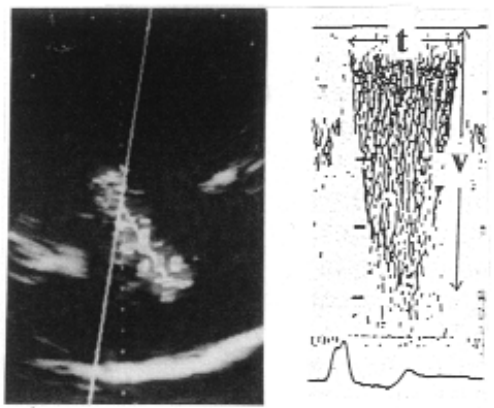

TR volume of one unit area at the center of base of TR jet

$$
\begin{aligned}
& V u=\int_{0}^{t} v(t) d t=\frac{2}{3} \cdot v t \\
& v=\text { peak velocity } \\
& t=\text { duration of regurgitation }
\end{aligned}
$$

\section{REGURGITANT VOLUME PER BEAT}

$$
\mathrm{V}_{\mathrm{TR}}=\frac{1}{3} \cdot \mathrm{S} \cdot \mathrm{Vu}=\frac{\pi}{18} \cdot \mathrm{abvt} \quad(\mathrm{cc} / \mathrm{beat})
$$

\section{( The sum of Vu per $\mathrm{S}$ builds up a conical shape )}

Fig 1. Calculation of TR volume per beat $\left(V_{T R}\right)$.

plasty was performed in 12 patients with a TAD of $\geq 45 \mathrm{~mm}$ to $49 \mathrm{~mm}$. In 12 patients with a TAD of $\geq 50 \mathrm{~mm}$, a modified De Vega annuloplasty, annuloplasty using a Carpentier ring (32 $\mathrm{mm}$ ), or tricuspid valve replacement was performed in 4 patients each. In the latter group, the method of treatment was not prospectively randomized. Tricuspid valve replacement was performed when there was severe long-standing functional TR associated with some degenerative changes at the edge of the cusps not detected by preoperative echocardiography. In these cases, annuloplasty procedures did not achieve a sufficient reduction of TR in the intraoperative evaluation and were promptly abandoned for a valve replace- 


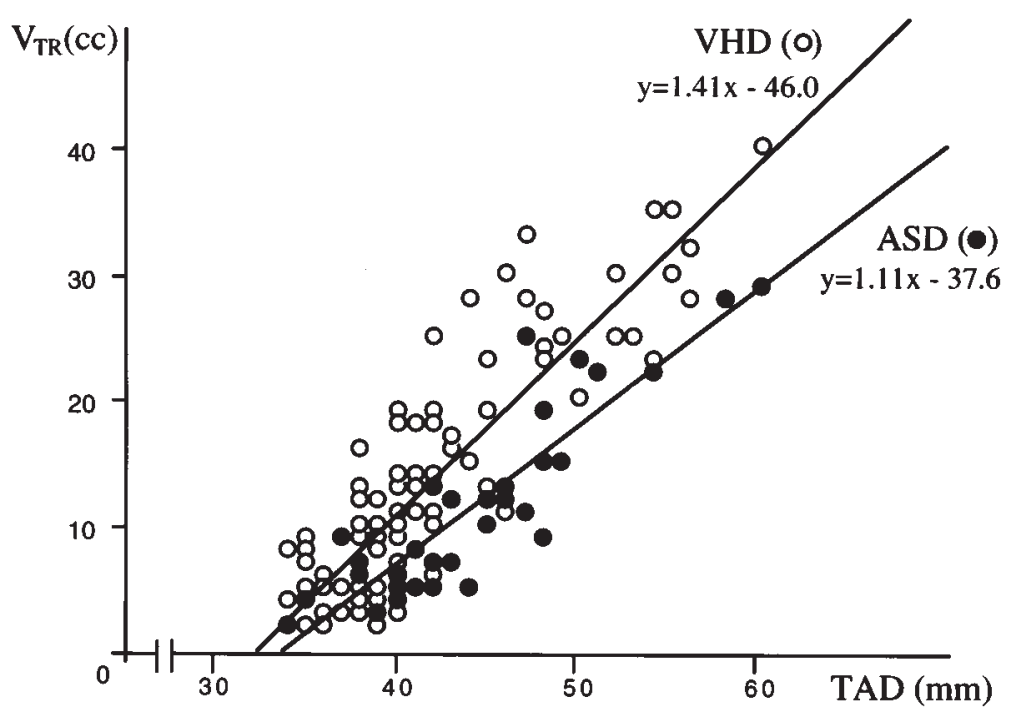

Fig 2. Correlation of regurgitant volume per beat $\left(V_{T R}\right)$ and TAD at end-diastole. There is a significant correlation between preoperative TAD and $\mathrm{V}_{\mathrm{TR}}$ in the VHD group $(r=0.87)$ and the ASD group $(r=0.88)$. However, the slope of the correlation line is steeper for the VHD group than for the ASD group.

ment. Mechanical (St Jude Medical, Inc, St Paul, Minn) or bioprosthetic valves (Carpentier-Edward pericardial valves; Baxter Healthcare Corp, Edwards Division, Santa Ana, Calif) were each used in 2 patients. In ASD, TR was ignored in 16 patients with a TAD of less than $45 \mathrm{~mm}$. A Kay annuloplasty was performed in 11 patients with a TAD of $\geq 45 \mathrm{~mm}$ to 49 $\mathrm{mm}$. All 5 patients with a TAD of $\geq 50 \mathrm{~mm}$ were treated with a modified De Vega annuloplasty.

The disappearance of regurgitation was confirmed intraoperatively by the injection of saline solution into the right ventricle after TR repair, and recently in combination with transesophageal echocardiography. In a modified De Vega annuloplasty, the anterior anulus was also repaired in addition to obliteration of the posterior leaflet. For a Kay or a modified De Vega annuloplasty, the dilated anulus was reduced to 2.5 fingerbreadths in the patients with VHD and 3 fingerbreadths in the patients with ASD, where the volume reduction of the right ventricle was likely due to closure of the ASD.

Follow-up. Except for 1 late death in the group with VHD, all patients have been followed up, with good repair of the primary cardiac lesions. None of them have undergone repeat operation. The follow-up period ranged from 6 to 130 months (mean, 79 months; median, 84 months). A postoperative catheterization study was performed 1 month after the operation at the same time as Doppler study in all patients. Echocardiograms and physical examinations were obtained every 6 months after the operation, and the most recent values of these data were used as the postoperative values. Good repair of the primary cardiac lesions was confirmed by postoperative Doppler study, which showed a functional mitral orifice area of greater than $2.5 \mathrm{~cm}^{2}$ and a pressure gradient across the aortic valve of below $30 \mathrm{~mm} \mathrm{Hg}$ with no perivalvular regurgitation in patients with VHD, and no leakage of the patch repair of the ASD.

Statistical analysis. Statistical analysis was performed with the Stat View 4.11 software package (Abacus Concepts, Inc, Berkeley, Calif). Values are expressed as the mean \pm standard deviation. Statistical differences were evaluated with unpaired or the paired Student $t$ test.

\section{Results}

Comparisons of the methods evaluating TR with the surgical procedure. With the conventional 4-grade classification based on the distance reached by TR jet in 2-dimensional Doppler echocardiography, ${ }^{14}$ it was difficult to decide on the treatment of TR, that is, repair or no repair, in patients with grade II and III disease. In contrast, the evaluation according to the $\mathrm{V}_{\mathrm{TR}}$ provided a clearer guideline for requirement of TR repair $\left(\mathrm{V}_{\mathrm{TR}}\right.$ $\geq 10 \mathrm{cc}$ ) before the operation (Fig 3).

Long-term changes in TR after repair. In the patients with VHD with a TAD of less than $40 \mathrm{~mm}$ and the patients with ASD with a TAD of less than $45 \mathrm{~mm}$, the $\mathrm{V}_{\mathrm{TR}}$ decreased gradually without TR repair (VHD, $5.3 \pm 2.3 \mathrm{cc}$ decreased to $1.8 \pm 2.0 \mathrm{cc}$; ASD, $4.5 \pm 2.0 \mathrm{cc}$ decreased to $0.8 \pm 1.2 \mathrm{cc}$ ). In the patients with VHD with a TAD of $\geq 40 \mathrm{~mm}$ to $49 \mathrm{~mm}$ and the patients with ASD with a TAD of $\geq 45 \mathrm{~mm}$ to $49 \mathrm{~mm}$, all patients experienced a decrease in the $\mathrm{V}_{\mathrm{TR}}$ to less than $5 \mathrm{cc}$ immediately after repair with a Kay or a modified De Vega annulo- 
Volume 117, Number 3

Table I. Preoperative profile of patients with VHD with a TAD of $<40 \mathrm{~mm}$ and of $\geq 40 \mathrm{~mm}$

\begin{tabular}{|c|c|c|c|c|c|}
\hline & $\begin{array}{c}T A D<40 \mathrm{~mm} \\
(n=39)\end{array}$ & $\begin{aligned} T A D & \geq 40 \mathrm{~mm} \\
(n & =57)\end{aligned}$ & $\mathrm{P}$ value & $\begin{array}{c}\text { Difference } \\
\text { of mean }\end{array}$ & $95 \% C I$ \\
\hline Age (yr) & $56.2 \pm 8.6$ & $54.4 \pm 8.5$ & .32 & -1.8 & -5.3 to 1.8 \\
\hline Sex (M:F) & 11:28 & $19: 38$ & & & \\
\hline NYHA class & $2.7 \pm 0.5$ & $3.1 \pm 0.6$ & $<.0001$ & 0.4 & 0.18 to 0.659 \\
\hline Hepatomegaly (fb) & $0.2 \pm 0.6$ & $2.5 \pm 1.6$ & $<.0001$ & 2.3 & 1.8 to 2.8 \\
\hline Indocyanine green $(\mathrm{k})$ & $0.140 \pm 0.040$ & $0.100 \pm 0.037$ & .0004 & -0.040 & -0.060 to -0.020 \\
\hline RAMP $(\mathrm{mm} \mathrm{Hg})$ & $4.6 \pm 2.6$ & $10.1 \pm 3.9$ & $<.0001$ & 5.5 & 4.1 to 6.9 \\
\hline RVEDP (mm Hg) & $6.3 \pm 2.7$ & $10.3 \pm 3.2$ & $<.0001$ & 4.0 & 2.8 to 5.3 \\
\hline RVSP (mm Hg) & $40.2 \pm 13.2$ & $45.5 \pm 14.1$ & .07 & 5.3 & -0.45 to 11.1 \\
\hline PAMP (mm Hg) & $26.7 \pm 7.8$ & $30.1 \pm 9.6$ & .12 & 3.4 & -0.2 to 7.0 \\
\hline $\operatorname{RVEDVI}\left(\mathrm{mL} / \mathrm{m}^{2}\right)$ & $111.3 \pm 20.3$ & $186.4 \pm 30.5$ & $<.0001$ & 75.1 & 63.9 to 86.3 \\
\hline RVEF (\%) & $53.1 \pm 4.8$ & $50.2 \pm 4.8$ & .06 & -2.9 & -4.9 to -0.9 \\
\hline
\end{tabular}

Values are expressed as mean \pm standard deviation. Statistical differences were evaluated with the unpaired Student $t$ test. $f b$, Finger-breadth below the right costal margin; $k, \mathrm{~K}$ value of indocyanine green measurement.

Table II. Preoperative profile of patients with ASD with a TAD of $<45 \mathrm{~mm}$ and of $\geq 45 \mathrm{~mm}$

\begin{tabular}{|c|c|c|c|c|c|}
\hline & $\begin{array}{c}T A D<45 \mathrm{~mm} \\
(n=16)\end{array}$ & $\begin{aligned} T A D & \geq 45 \mathrm{~mm} \\
(n & =16)\end{aligned}$ & $\mathrm{P}$ value & $\begin{array}{l}\text { Difference } \\
\text { of mean }\end{array}$ & $95 \% C I$ \\
\hline Age (yr) & $49.5 \pm 12.6$ & $54.9 \pm 9.2$ & .18 & 5.4 & -2.6 to 13.3 \\
\hline Sex (M:F) & $5: 11$ & $9: 7$ & & & \\
\hline NYHA class & $1.9 \pm 0.6$ & $3.0 \pm 0.7$ & $<.0001$ & 1.1 & 0.59 to 1.54 \\
\hline Hepatomegaly (fb) & $0.3 \pm 0.6$ & $2.2 \pm 1.5$ & $<.0001$ & 1.9 & 1.0 to 2.7 \\
\hline Indocyanine green $(\mathrm{k})$ & $0.156 \pm 0.007$ & $0.086 \pm 0.031$ & .0037 & -0.07 & -0.11 to -0.03 \\
\hline RAMP (mm Hg) & $4.0 \pm 1.9$ & $8.6 \pm 3.1$ & $<.0001$ & 4.6 & 2.8 to 6.5 \\
\hline RVEDP (mm Hg) & $6.5 \pm 2.7$ & $10.8 \pm 3.1$ & .0003 & 4.3 & 2.2 to 6.3 \\
\hline $\operatorname{RVSP}(\mathrm{mm} \mathrm{Hg})$ & $35.9 \pm 9.8$ & $56.3 \pm 18.3$ & .0005 & 20.4 & 9.7 to 30.9 \\
\hline PAMP (mm Hg) & $18.9 \pm 3.7$ & $32.6 \pm 10.6$ & $<.0001$ & 13.7 & 7.7 to 19.7 \\
\hline $\operatorname{RVEDVI}\left(\mathrm{mL} / \mathrm{m}^{2}\right)$ & $174.4 \pm 10.5$ & $226.3 \pm 19.1$ & .0001 & 51.9 & 40.7 to 63.0 \\
\hline $\operatorname{RVEF}(\%)$ & $54.3 \pm 4.9$ & $51.3 \pm 3.2$ & .06 & -3.0 & -6.0 to -0.03 \\
\hline
\end{tabular}

Values are expressed as the \pm standard deviation. Statistical differences were evaluated with the unpaired Student $t$ test. $f b$, Finger-breadth below the right costal margin; $k$, $\mathrm{K}$ value of indocyanine green measurement.

plasty (VHD, $15.6 \pm 3.2 \mathrm{cc}$ decreased to $1.8 \pm 1.9 \mathrm{cc}$; ASD, $13.2 \pm 2.6 \mathrm{cc}$ decreased to $1.2 \pm 1.9 \mathrm{cc}$ ) and no recurrence of $\mathrm{V}_{\mathrm{TR}}$ late after the operation. In the patients with VHD with a TAD of $50 \mathrm{~mm}$ or more, 8 patients have had a significant decrease in the $\mathrm{V}_{\mathrm{TR}}$ to less than 5 cc immediately after the creation of a Carpentier ring or tricuspid valve replacement $(29.0 \pm 6.5 \mathrm{cc}$ decreased to $1.4 \pm 1.8 \mathrm{cc}$ ) with no late recurrence of $\mathrm{V}_{\mathrm{TR}}$. The remaining 4 patients had an immediate remarkable regression of TR after a modified De Vega annuloplasty (24.0 \pm 4.5 cc decreased to $5.4 \pm 2.0 \mathrm{cc}$ ) but had a recurrence of the $\mathrm{V}_{\mathrm{TR}}$ to above $10 \mathrm{cc}$ late after the operation. In contrast, all 5 patients with ASD in this category showed a remarkable decrease in the $\mathrm{V}_{\mathrm{TR}}$ to less than $5 \mathrm{cc}$ after a modified De Vega annuloplasty $(24.8 \pm 3.1 \mathrm{cc}$ decreased to $2.2 \pm 1.8 \mathrm{cc}$ ) and have had no recurrence of $\mathrm{V}_{\mathrm{TR}}$.

Changes in degree of heart failure after operation. In the patients in whom TR was not treated, NYHA functional class has significantly improved in those patients with VHD and those patients with ASD $(2.7 \pm$ 0.5 to $1.3 \pm 0.5$ and $1.9 \pm 0.6$ to $1.1 \pm 0.3 ; P<.0001$, respectively). Hepatomegaly, RAMP, RVEDP, and RVEDVI have not shown any deterioration in both groups.

In the patients with repair of the tricuspid valve, hepatomegaly, RAMP, RVEDP, pulmonary arterial mean pressure (PAMP), RVEDVI, and NYHA functional class significantly improved in both groups. In the patients with VHD with a TAD of $50 \mathrm{~mm}$ or more, however, these parameters significantly improved but still remained less good than in those patients with a TAD of $\geq 40 \mathrm{~mm}$ to $49 \mathrm{~mm}$ (Table III). In addition, 4 patients who underwent a modified De Vega annuloplasty had a gradual increase in clinical manifestations; 1 of them died of right heart failure late after operation. The other 8 patients who underwent annuloplasty with 
Table III. Postoperative right heart failure parameters for patients with VHD who underwent TR repair

\begin{tabular}{|c|c|c|c|c|c|}
\hline & $\begin{array}{c}T A D \geq 40 \mathrm{~mm}-49 \mathrm{~mm} \\
(n=45)\end{array}$ & $\begin{aligned} T A D & \geq 50 \mathrm{~mm} \\
(n & =12)\end{aligned}$ & $\mathrm{P}$ value & $\begin{array}{l}\text { Difference } \\
\text { of mean }\end{array}$ & $95 \% C I$ \\
\hline NYHA class & $1.3 \pm 0.5$ & $2.2 \pm 0.9$ & $<.0001$ & 0.9 & 0.52 to 1.31 \\
\hline Hepatomegaly (fb) & $0.4 \pm 0.6$ & $2.0 \pm 1.2$ & $<.0001$ & 1.6 & 1.1 to 2.1 \\
\hline RAMP (mm Hg) & $7.0 \pm 1.8$ & $9.4 \pm 2.3$ & .00016 & 2.4 & 1.2 to 3.6 \\
\hline RVEDP (mm Hg) & $6.6 \pm 3.0$ & $9.9 \pm 1.9$ & .0028 & 3.3 & 1.2 to 5.4 \\
\hline PAMP (mm Hg) & $22.8 \pm 6.6$ & $22.8 \pm 3.5$ & .98 & 0 & -4.6 to 4.5 \\
\hline $\operatorname{RVEDVI}\left(\mathrm{mL} / \mathrm{m}^{2}\right)$ & $118.5 \pm 18.5$ & $150.2 \pm 25.3$ & .0036 & 31.7 & 4.5 to 58.9 \\
\hline RVEF (\%) & $52.7 \pm 3.2$ & $48.8 \pm 1.5$ & .030 & -3.9 & -7.5 to -0.44 \\
\hline
\end{tabular}

Values are expressed as the mean \pm standard deviation. Statistical differences were evaluated with the unpaired Student $t$ test. $f b$, Finger-breadth below the right costal margin.

Table IV. Postoperative right heart failure parameters for patients with ASD who underwent TR repair

\begin{tabular}{|c|c|c|c|c|c|}
\hline & $\begin{array}{c}T A D \geq 45 \mathrm{~mm}-49 \mathrm{~mm} \\
(n=11)\end{array}$ & $\begin{array}{c}T A D \geq 50 \mathrm{~mm} \\
(n=5)\end{array}$ & P value & $\begin{array}{l}\text { Difference } \\
\text { of mean }\end{array}$ & $95 \%$ CI \\
\hline NYHA class & $1.3 \pm 0.5$ & $1.5 \pm 0.4$ & .41 & 0.2 & -0.4 to 0.8 \\
\hline Hepatomegaly (fb) & $0.2 \pm 0.4$ & $1.0 \pm 0.7$ & .01 & 0.8 & 0.2 to 1.4 \\
\hline RAMP (mm Hg) & $4.4 \pm 1.8$ & $5.2 \pm 1.9$ & .56 & 0.8 & -2.9 to 4.5 \\
\hline RVEDP (mm Hg) & $5.4 \pm 2.0$ & $5.2 \pm 1.9$ & .90 & -0.2 & -3.8 to 3.4 \\
\hline PAMP (mm Hg) & $24.2 \pm 6.0$ & $26.0 \pm 5.1$ & .74 & 1.8 & -10.5 to 14.1 \\
\hline $\operatorname{RVEDVI}\left(\mathrm{mL} / \mathrm{m}^{2}\right)$ & $138.5 \pm 14.0$ & $145.7 \pm 22.5$ & .46 & 7.2 & -12.8 to 27.2 \\
\hline $\operatorname{RVEF}(\%)$ & $52.2 \pm 2.9$ & $49.3 \pm 9.4$ & .40 & -2.9 & -9.9 to 4.1 \\
\hline
\end{tabular}

Values are expressed as the mean \pm standard deviation. Statistical differences were evaluated with the unpaired Student $t$ test. $f b$, Finger-breadth below the right costal margin.

a Carpentier ring or valve replacement have shown no deterioration of these parameters. In contrast, all 5 patients with ASD with a TAD of $\geq 50 \mathrm{~mm}$ showed significant improvement of these values to the same extent as did those patients with a TAD of $\geq 45 \mathrm{~mm}$ to $49 \mathrm{~mm}$ even after a modified De Vega annuloplasty (Table IV).

Retrospective analyses of preoperative parameters in patients who underwent TR repair. In the retrospective preoperative analyses, disappearance rate of indocyanine green ( $\mathrm{k}$ value), RAMP, RVEDP, right ventricular systolic pressure (RVSP), and right ventricular ejection fraction (RVEF) showed significant decreased values in the patients with TAD of $50 \mathrm{~mm}$ or more when compared with those patients with a TAD of $\geq 40 \mathrm{~mm}$ to $49 \mathrm{~mm}$ in the VHD group. In contrast, no significant differences were seen between the patients with a TAD of $\geq 50 \mathrm{~mm}$ and a TAD of $\geq 45 \mathrm{~mm}$ to 49 $\mathrm{mm}$ in the ASD group (Tables V and VI).

\section{Discussion}

TR has been evaluated qualitatively by both invasive and noninvasive measurements, but these assessments are sometimes unreliable because of their individual shortcomings. ${ }^{14-16}$ Right ventriculography sometimes causes artificial regurgitation by the catheter, and the distance reached by TR jet in color Doppler echocardiography has the variant gradings from the thin and long jet to the thick and short jet. Our quantitative method is based on the fact that $\mathrm{V}_{\mathrm{TR}}$ is equal to the sum of the regurgitant volume of 1 unit area at the base of $\mathrm{TR}$. The $\mathrm{V}_{\mathrm{TR}}$ was calculated as the product of the crosssectional area of the regurgitant jet and the regurgitant volume of 1 unit area, which are obtained from Doppler ultrasound measurements at the base of the TR jet. Therefore, even if the TR jet radiates like a fountain or impinges on the atrial wall, the $\mathrm{V}_{\mathrm{TR}}$ can be calculated by measurements made at its base. This is the great advantage of this method. The problems are that $\mathrm{V}_{\mathrm{TR}}$ is not necessarily reproducible depending on circumstances and a smaller $\mathrm{V}_{\mathrm{TR}}$ may be estimated than the actual regurgitant volume, because of our assumption of the sum of the regurgitant volume of 1 unit area per cross-sectional area building up a conical shape. However, interobserver differences were scarcely seen when the Doppler study was performed in the patient with hemodynamic stability. ${ }^{17}$ In addition, the evaluation with $\mathrm{V}_{\mathrm{TR}}$ could potentially provide a clearer guideline for TR repair $\left(\mathrm{V}_{\mathrm{TR}} \geq 10 \mathrm{cc}\right)$ when compared with the conventional 4-grade classifications, ${ }^{14}$ as shown in Fig 3. 
Volume 117, Number 3

Table V. Preoperative profile of patients with VHD with a TAD of $\geq 40 \mathrm{~mm}$ to $49 \mathrm{~mm}$ and $\geq 50 \mathrm{~mm}$

\begin{tabular}{|c|c|c|c|c|c|}
\hline & $\begin{array}{c}T A D \geq 40 \mathrm{~mm}-49 \mathrm{~mm} \\
(n=45)\end{array}$ & $\begin{array}{c}T A D \geq 50 \mathrm{~mm} \\
(n=12)\end{array}$ & $\mathrm{P}$ value & $\begin{array}{l}\text { Difference } \\
\text { of mean }\end{array}$ & $95 \% C I$ \\
\hline Age (yr) & $54.5 \pm 8.8$ & $54.3 \pm 7.3$ & .94 & -0.2 & -5.8 to 5.4 \\
\hline Sex (M:F) & 15:30 & $4: 8$ & & & \\
\hline NYHA class & $3.0 \pm 0.6$ & $3.4 \pm 0.5$ & .021 & 0.4 & 0.07 to 0.81 \\
\hline Hepatomegaly (fb) & $2.1 \pm 1.4$ & $4.2 \pm 0.9$ & $<.0001$ & 2.1 & 1.2 to 2.9 \\
\hline Indocyanine green $(\mathrm{k})$ & $0.112 \pm 0.032$ & $0.088 \pm 0.040$ & .0043 & -0.024 & -0.050 to -0.002 \\
\hline RAMP $(\mathrm{mm} \mathrm{Hg})$ & $8.5 \pm 3.2$ & $14.1 \pm 3.7$ & $<.0001$ & 5.6 & 3.4 to 7.8 \\
\hline RVEDP (mm Hg) & $9.7 \pm 2.9$ & $12.5 \pm 3.5$ & .0065 & 2.8 & 0.8 to 4.7 \\
\hline RVSP (mm Hg) & $47.9 \pm 14.6$ & $36.5 \pm 8.0$ & .01 & -11.4 & -20.1 to -2.7 \\
\hline PAMP (mm Hg) & $31.4 \pm 10.9$ & $24.5 \pm 5.1$ & .03 & -6.9 & -12.7 to -1.1 \\
\hline $\operatorname{RVEDVI}\left(\mathrm{mL} / \mathrm{m}^{2}\right)$ & $177.1 \pm 24.7$ & $221.3 \pm 25.0$ & $<.0001$ & 44.2 & 28.0 to 60.3 \\
\hline $\operatorname{RVEF}(\%)$ & $51.8 \pm 3.8$ & $44.2 \pm 3.2$ & $<.0001$ & -7.6 & -10.0 to -5.3 \\
\hline
\end{tabular}

Values are expressed as the mean \pm standard deviation. Statistical differences were evaluated using unpaired Student's $t$ text. $f b$, Finger-breadth below the right costal margin; $k$, $\mathrm{K}$ value of indocyanine green measurement.

Table VI. Preoperative profile of patients with ASD with a TAD of $\geq 45 \mathrm{~mm}$ to $49 \mathrm{~mm}$ and $\geq 50 \mathrm{~mm}$

\begin{tabular}{|c|c|c|c|c|c|}
\hline & $\begin{array}{c}T A D \geq 45 \mathrm{~mm}-49 \mathrm{~mm} \\
(n=11)\end{array}$ & $\begin{array}{c}T A D \geq 50 \mathrm{~mm} \\
(n=5)\end{array}$ & $\mathrm{P}$ value & $\begin{array}{l}\text { Difference } \\
\text { of mean }\end{array}$ & $95 \% C I$ \\
\hline Age (yr) & $56.7 \pm 9.5$ & $50.8 \pm 8.0$ & .25 & -5.9 & -16.4 to 4.6 \\
\hline Sex (M:F) & $3: 8$ & $2: 3$ & & & \\
\hline NYHA class & $2.7 \pm 0.6$ & $3.6 \pm 0.5$ & .021 & 0.9 & 0.16 to 1.59 \\
\hline Hepatomegaly (fb) & $1.5 \pm 0.9$ & $3.8 \pm 1.3$ & $<.001$ & 2.3 & 1.1 to 3.6 \\
\hline Indocyanine green (k) & $0.086 \pm 0.040$ & $0.085 \pm 0.010$ & .96 & -0.001 & -0.05 to 0.05 \\
\hline RAMP (mm Hg) & $7.5 \pm 3.0$ & $9.4 \pm 4.6$ & .08 & 1.9 & -1.5 to 5.3 \\
\hline RVEDP (mm Hg) & $9.8 \pm 2.8$ & $12.0 \pm 4.2$ & .07 & 2.2 & -0.6 to 5.0 \\
\hline RVSP (mm Hg) & $54.1 \pm 21.5$ & $59.4 \pm 9.4$ & .66 & 5.3 & -17.2 to 27.8 \\
\hline PAMP (mm Hg) & $33.1 \pm 12.6$ & $31.6 \pm 4.7$ & .80 & -1.5 & -14.2 to 11.2 \\
\hline $\operatorname{RVEDVI}\left(\mathrm{mL} / \mathrm{m}^{2}\right)$ & $215.9 \pm 10.9$ & $249.0 \pm 11.4$ & $<.0001$ & 33.1 & 20.3 to 45.9 \\
\hline $\operatorname{RVEF}(\%)$ & $52.2 \pm 2.9$ & $49.3 \pm 3.1$ & .09 & -2.9 & -6.3 to 0.5 \\
\hline
\end{tabular}

Values are expressed as the mean \pm standard deviation. Statistical differences were evaluated using unpaired Student's $t$ test. $f b$, Finger-breadth below the right costal margin; $k, \mathrm{~K}$ value of indocyanine green measurement.

Functional TR is first originated by right ventricular pressure or volume overload, with VHD causing the former and ASD causing the latter. This is supported by the result that PAMP in the patients with insignificant TR was significantly lower in patients with ASD than in patients with VHD (Tables I and II). Furthermore, development of TR causes volume overload on the right ventricle by TR itself along with dilation of the tricuspid anulus. ${ }^{18,19}$ In support of this finding, the present study showed that the preoperative $\mathrm{V}_{\mathrm{TR}}$ was directly proportional to the TAD in the VHD and ASD groups, respectively. In addition in ASD, a left-to-right shunt flow augments such volume loading. This may explain the steeper slope for the correlation line for the relationship between TAD and $\mathrm{V}_{\mathrm{TR}}$ in VHD, when compared with in ASD. That is, the TR volume was smaller in quantity in ASD than VHD when the TAD was equal.
Regarding estimation of the TAD, the TAD proved to be reproducible regardless of the size or geometry of the right ventricle. The TAD was associated with evidence of right heart failure, and the patients with VHD with a TAD of $\geq 40 \mathrm{~mm}$ and the patients with ASD with a TAD of $\geq 45 \mathrm{~mm}$ required TR repair. Most of them experienced remarkable improvement in TR and hemodynamic and clinical findings after a Kay or a modified De Vega annuloplasty. In the patients with severely dilated anulus, however, the long-term changes of TR differed somewhat between those patients with VHD and ASD. In fact, in the patients with VHD with a TAD of $\geq 50$ $\mathrm{mm}$, the right heart parameters still remained less good when compared with those patients with a TAD of $<50$ $\mathrm{mm}$. In addition, 4 patients who underwent a modified De Vega annuloplasty experienced a gradual increase in TR and clinical manifestations late after the operation. In contrast, in the patients with ASD in this category, 


\section{2-DD}

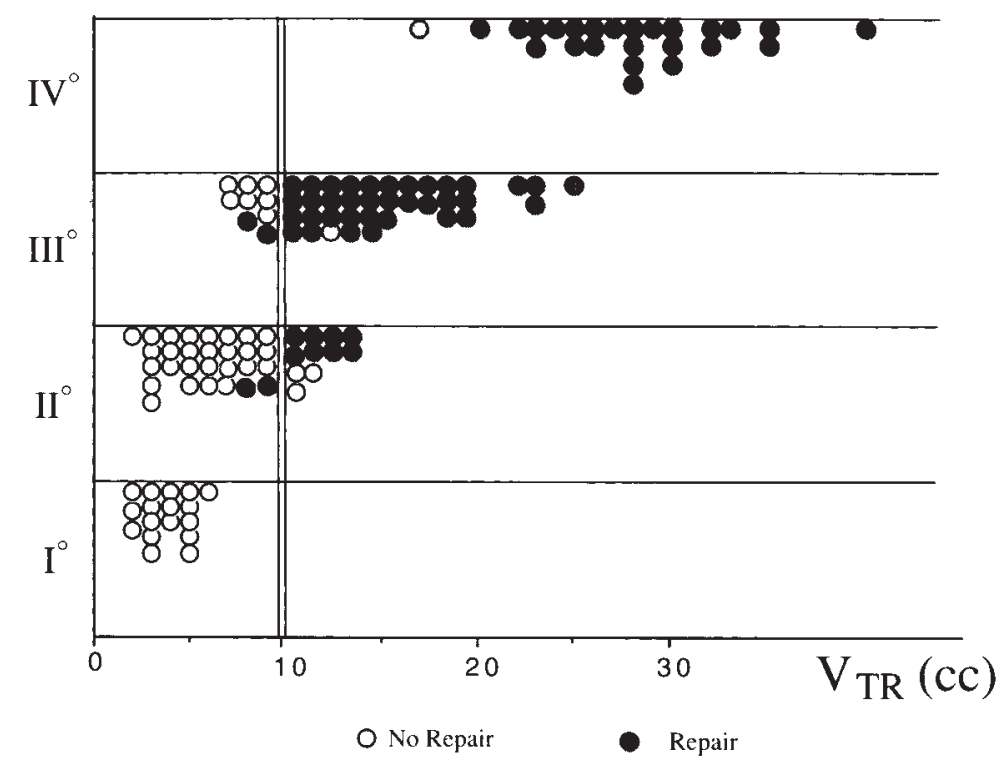

Fig 3. Comparisons of the methods used to evaluate the TR with the surgical procedure. With the conventional 4-grade classification based on the distance reached by TR jet in 2-dimensional Doppler echocardiography $(2-D D),{ }^{14}$ it is difficult to select the treatment for TR, that is, repair or no repair, in patients with grade II and III disease. The evaluation according to $\mathrm{V}_{\mathrm{TR}}$ provides a clearer guideline for TR repair $\left(\mathrm{V}_{\mathrm{TR}} \geq\right.$ $10 \mathrm{cc}$ ) before the operation.

these right heart parameters significantly improved to the same extent as in those patients with a TAD of $<50$ $\mathrm{mm}$ and have experienced no deterioration even after a modified De Vega annuloplasty. This might indicate that De Vega annuloplasty is sufficient for ASD, although a more rigid annuloplasty method or valve replacement is mandatory for VHD in this category.

The retrospective preoperative analyses revealed that the patients with VHD with a TAD of $\geq 50 \mathrm{~mm}$ showed lower RVSP and RVEF (Table V). However, previous studies ${ }^{20,21}$ have demonstrated that more severe TR is accompanied by higher RVSP. We believe that the forward flow of the right ventricle decreases with progression of TR. As a result, such a severe TR in this category would have a lower RVSP because of right ventricular dysfunction, indicative of a lower RVEF, as was proved in this study. In contrast, the patients with ASD with a TAD of $\geq 50 \mathrm{~mm}$ did not show such a decrease in RVSP and RVEF. This indicates that in ASD, right ventricular function did not deteriorate to the same extent as in VHD, even in this category. This would be the reason that the postoperative change of TR differed between those patients with VHD and ASD in this category.

We thank Dr Yoshimasa Maniwa for statistical consultation.

\section{REFERENCES}

1. Braunwald NS, Ross J Jr, Morrow AG. Conservative management of tricuspid regurgitation in patients undergoing mitral valve replacement. Circulation 1967;35(Suppl):I63-9.

2. Kay JH, Maselli-Champagna G, Tsuji HK. Surgical treatment of tricuspid insufficiency. Ann Surg 1965;162:53-8.

3. Boyd AD, Engelman RM, Isom OW, Reed GE, Spencer FC. Tricuspid annuloplasty: five and one-half years' experience with 78 patients. J Thorac Cardiovasc Surg 1974;68:344-51.

4. Carpentier A, Deloche A, Hanania G, et al. Surgical management of acquired tricuspid valve disease. J Thorac Cardiovasc Surg 1974;67:53-65.

5. Cohn LH. Tricuspid regurgitation secondary to mitral valve disease: when and how to repair. J Card Surg 1994;9(suppl):II23741.

6. Cohen SR, Sell JE, McIntosh CC, Clarke RE. Tricuspid regurgitation in patients with acquired chronic, pure mitral regurgitation: nonoperative management, tricuspid annuloplasty and tricuspid valve replacement. J Thorac Cardiovasc Surg 1987;94:488-97.

7. Nakano S, Kawashima Y, Hirose H, et al. Evaluation of long-term results of bicuspidalization annuloplasty for functional tricuspid regurgitation: a seventeen-year experience with 133 consecutive patients. J Thorac Cardiovasc Surg 1988;95:340-5.

8. Kay LG, Morita S, Mendez MA, Zubiate P, Kay HJ. Tricuspid regurgitation associated with mitral valve disease: repair and replacement. Ann Thorac Surg 1989;48:593-5.

9. McGrath LB, Gonzalez-Lavin L, Bailey BM, Grunkemeier GL, Fernandez J, Laub GW. Tricuspid valve operations in 530 patients. J Thorac Cardiovasc Surg 1990;99:124-33. 
10. Mullany CJ, Gersh BJ, Orzulak TA, et al. Repair of tricuspid valve insufficiency in patients undergoing double (aortic and mitral) valve replacement: perioperative mortality and long-term ( 1 to 20 years) follow-up in 109 patients. J Thorac Cardiovasc Surg 1987;94:740-8.

11. Singh AK, Feng WC, Sanofsky SJ. Long-term results of St Jude Medical valve in the tricuspid position. Ann Thorac Surg 1992;54:538-40.

12. Scully HE, Armstrong CS. Tricuspid valve replacement: fifteen years of experience with mechanical prostheses and bioprostheses. J Thorac Cardiovasc Surg 1995;109:1035-41.

13. Ferlinz J, Gorlin R, Cohn PF, Herman M. Right ventricular performance in patients with coronary artery disease. Circulation 1975;52:608-15.

14. Miyatake K, Okamoto M, Kinoshita N, et al. Evaluation of tricuspid regurgitation by pulsed Doppler and two-dimensional echocardiography. Circulation 1982;66:777-84.

15. Carreras F, Borras X, Auge JM, Pons-Llado G. Pulsed Doppler assessment of tricuspid regurgitation: usefulness of regurgitant signal patterns for estimation of severity. Angiology 1988;39: 788-94.

16. Suzuki Y, Kambara H, Kadota K, et al. Detection and evaluation of tricuspid regurgitation using a real-time, two-dimensional, color-coded, Doppler flow imaging system: comparison with contrast two-dimensional echocardiography and right ventriculography. Am J Cardiol 1986;57:811-5.

17. Sugimoto T, Ota T, Nakamura K. New method quantifying tricuspid regurgitant volume by two-dimensional color and continuous wave Doppler echocardiography. J Cardiol (in Japanese) 1988; 18:1069-81.

18. Tei C, Pilgrim JP, Shah PM, Ormiston JA, Wong M. The tricuspid valve annulus: study of size and motion in normal subjects and in patients with tricuspid regurgitation. Circulation 1982; 66:665-71.

19. Mikami T, Kudo T, Sakurai N, Sakamoto S, Tanabe Y, Yasuda H. Mechanisms for development of functional tricuspid regurgitation by pulsed Doppler and two-dimensional echocardiography. Am J Cardiol 1984;53:160-3.

20. Yock PG, Popp RL. Noninvasive estimation of right ventricular systolic pressure by Doppler ultrasound in patients with tricuspid regurgitation. Circulation 1984;70:657-62.

21. Morrison DA, Ovitt T, Hammermeister KE, Stovall LR. Functional tricuspid regurgitation and right ventricular dysfunction in pulmonary hypertension. Am J Cardiol 1988;62:108-12.

\section{Timely}

The Journal of Thoracic and Cardiovascular Surgery delivers the information you need now. Articles usually appear within four months of acceptance. 